\title{
REFLEXÕES FENOMENOLÓGICAS SOBRE JOVEM ARTE CONTEMPORÂNEA: FORMAS DE SOBREVIVÊNCIA NAS OBRAS DE INÊS MOURA.
}

\author{
PHENOMENOLOGICAL REFLEXIONS ABOUT YOUNG CONTEMPORARY ART: \\ SURVIVAL FORMS IN INÊS MOURA'S ARTWORKS.
}

\author{
Juliana Froehlich ${ }^{1}$ \\ (University of Antwerp | CAPES - Ministry of Education of Brazil) \\ jufroehlich@usp.br
}

Recibido: 10/05/2018

Aprobado: 11/07/2018

\begin{abstract}
RESUMO
O presente artigo debruça-se sobre um conjunto de obras de arte da artista visual Inês Moura, a saber, duas fotografias da série Paisagens (2012), três fotografias do estudo Our relationship explained by nature \#1 (2012) e a instalação e site-specific Herbarium in loco (2011). São temas e motivos das obras que encaminham este texto: muros em ruínas, uma hera que espalha suas raízes sobre um muro, a vegetação que toma uma construção, plantas, folhas e galhos que ocupam um espaço vazio de concreto. Junto à tensão entre vegetações e construções, os trabalhos apresentam as indagações sobre ser 'jovem' artista no circuito da arte contemporânea. Uma vez que compreendemos que Inês, pintora de formação, pensa e 'retrata' seus motivos, assim como, o mundo em que habita. Na forma das obras e em seus motivos encontramos indícios da margem, da tensão e da sobrevivência de organismos de modo que sobrevivência se apresenta como a noção por onde interpretamos a situação do chamado 'jovem artista'. Refletimos aqui, portanto, sobre a forma com a qual a obra se apresenta, sobre seu conteúdo e sobre o contexto da arte contemporânea.
\end{abstract}

Palavras-chaves: arte contemporânea, fenomenologia, jovem artista

\section{ABSTRACT}

This article examines a set of artworks produced by the visual artist Inês Moura, which are two photographs from the series called Paisagens | Landscapes (2012); three photographs from the study Our relationship explained by nature \#1 (2012); and the installation and sitespecific Herbarium in loco (2011). The motives and themes of the artworks, such as ruins, an ivy that spreads its roots over a wall, vegetation that overcomes a construction and plants, leaves and branches that occupy a space of concrete, are the basis for the interpretations explored in this paper. Along with the tension between vegetation and constructions, this paper presents reflections about being a 'young' artist in the circuit of contemporary art. Inês, a graduated painter, thinks and 'portrays' her motives, as well as the world she lives in. In the form of works and their motives, it is possible to find vestiges of the margin, the tension and the survival of organisms. Thus, survival is a key notion present in the artworks that are

\footnotetext{
${ }^{1}$ Juliana Froehlich é doutoranda em Film Studies and Visual Culture na University of Antwerp (Bélgica) e bolsista CAPES. Atualmente, pesquisa sobre experimentalismo, práticas de vanguarda e abstração em artes visuais e cinema. Ela publicou sobre métodos de pesquisa em arte contemporânea e apresentou em conferências sobre as relações entre artes visuais e cinema. É mestre pelo Programa de PósGraduação Interunidades em Estética e História da Arte da Universidade de São Paulo (2013), na Linha de Pesquisa Metodologia e Epistemologia da Arte, onde foi Bolsista CAPES. Psicóloga e Bacharel em Psicologia pela Universidade de São Paulo (2010) com intercâmbio na Université Paris 8. Tem experiência na área de Artes Visuais (artes plásticas, vídeo e cinema) com ênfase em Crítica e Teoria das Artes Visuais. Em 2014, foi assistente do departamento de acervo e pesquisa da associação cultural Videobrasil.
} 
the basis to interpret the situation of the so-called 'young artist'. We reflect here, therefore, on the way in which the work is presented, its content and the context of contemporary art.

Keywords: contemporary art, phenomenology, young artist
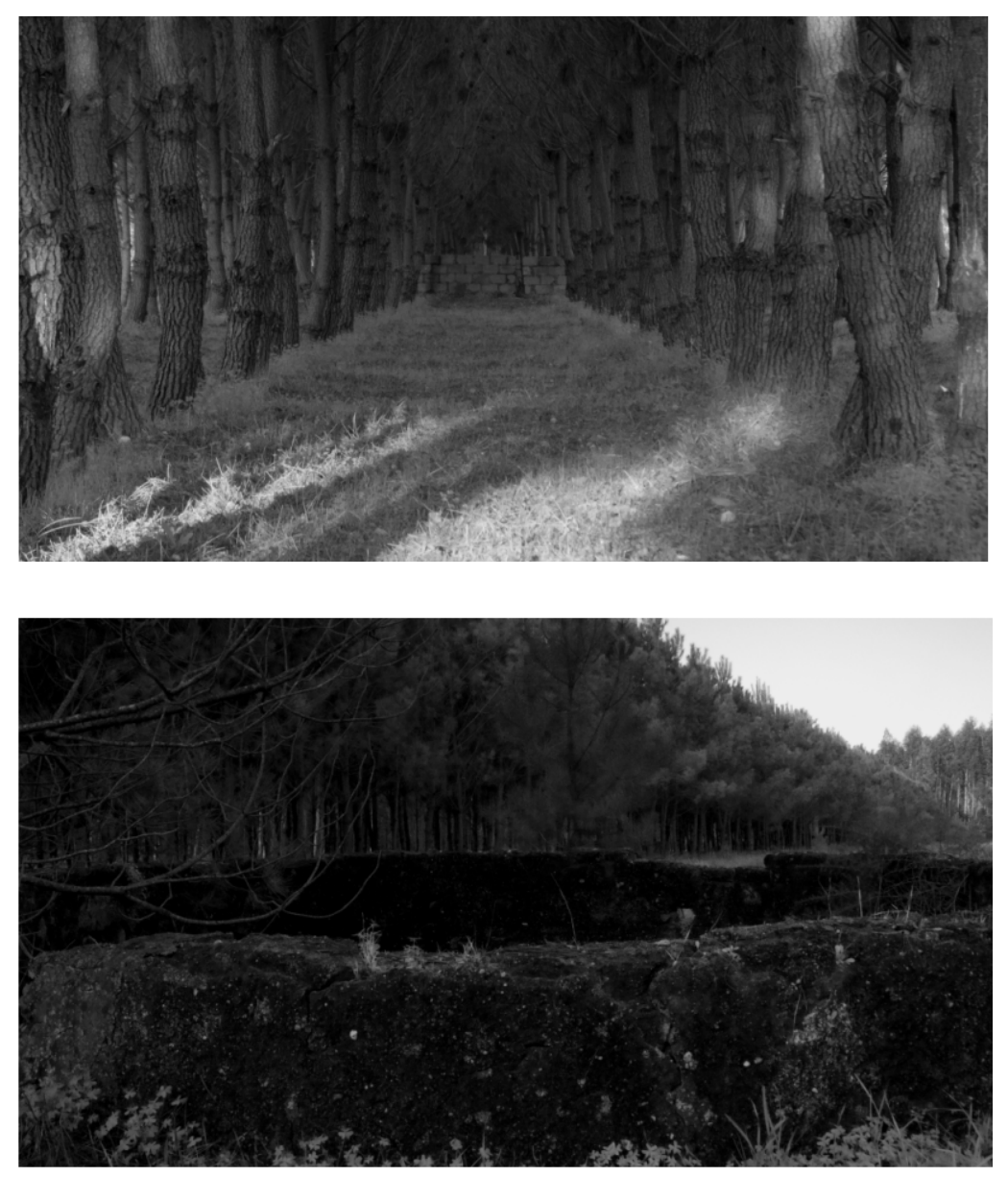

Imagem 1: Paisagens, 2012

Impressão a jato de tinta sobre papel fotográfico.

26,5 x $47 \mathrm{~cm}$.

Foto: Inês Moura. 

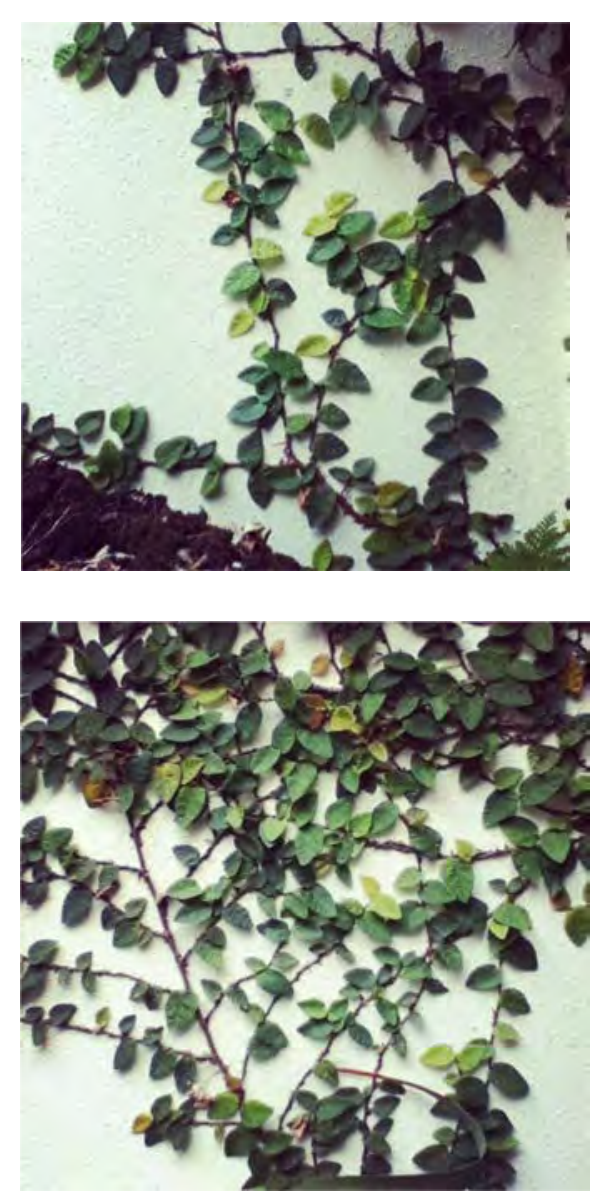

Imagem 2: Our Relationship Explained by Nature \#1, 2012

Estudos para o projeto de desenho Our Relationship Explained by Nature \#2

Fotos: Inês Moura

Montagem nossa

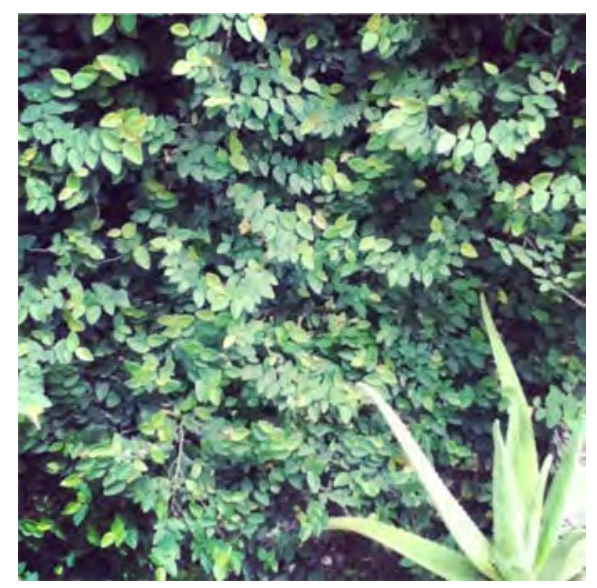



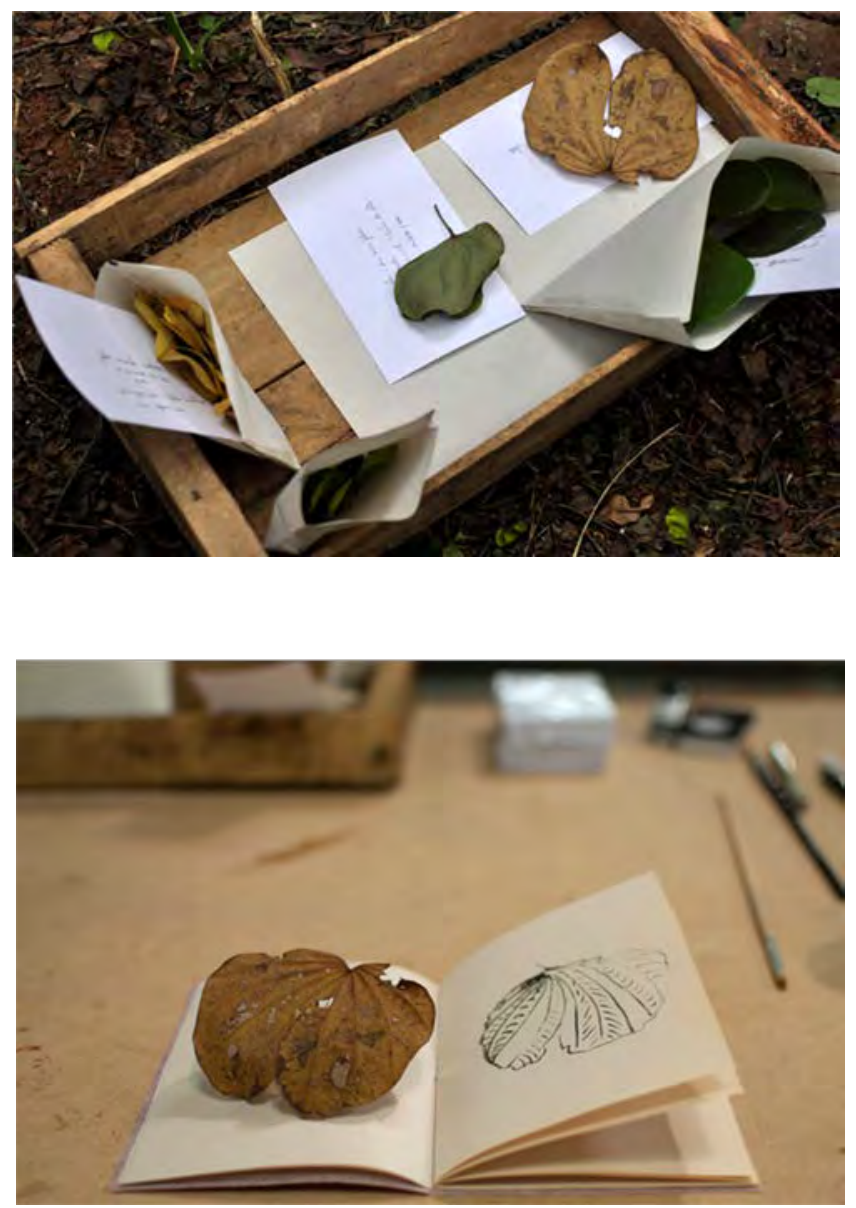

Imagem 3: Fotos de Inês Moura para a instalação Herbarium in loco (2011). Foto: Inês Moura Montagem nossa

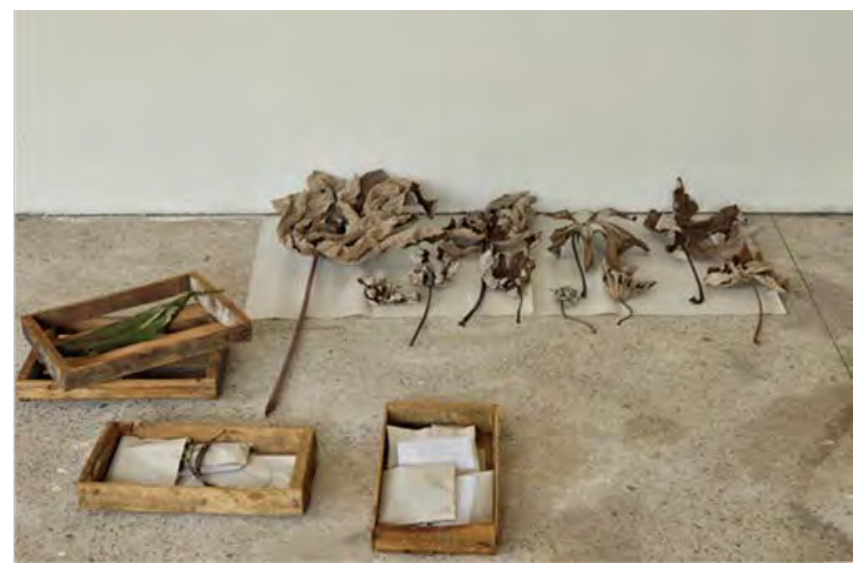




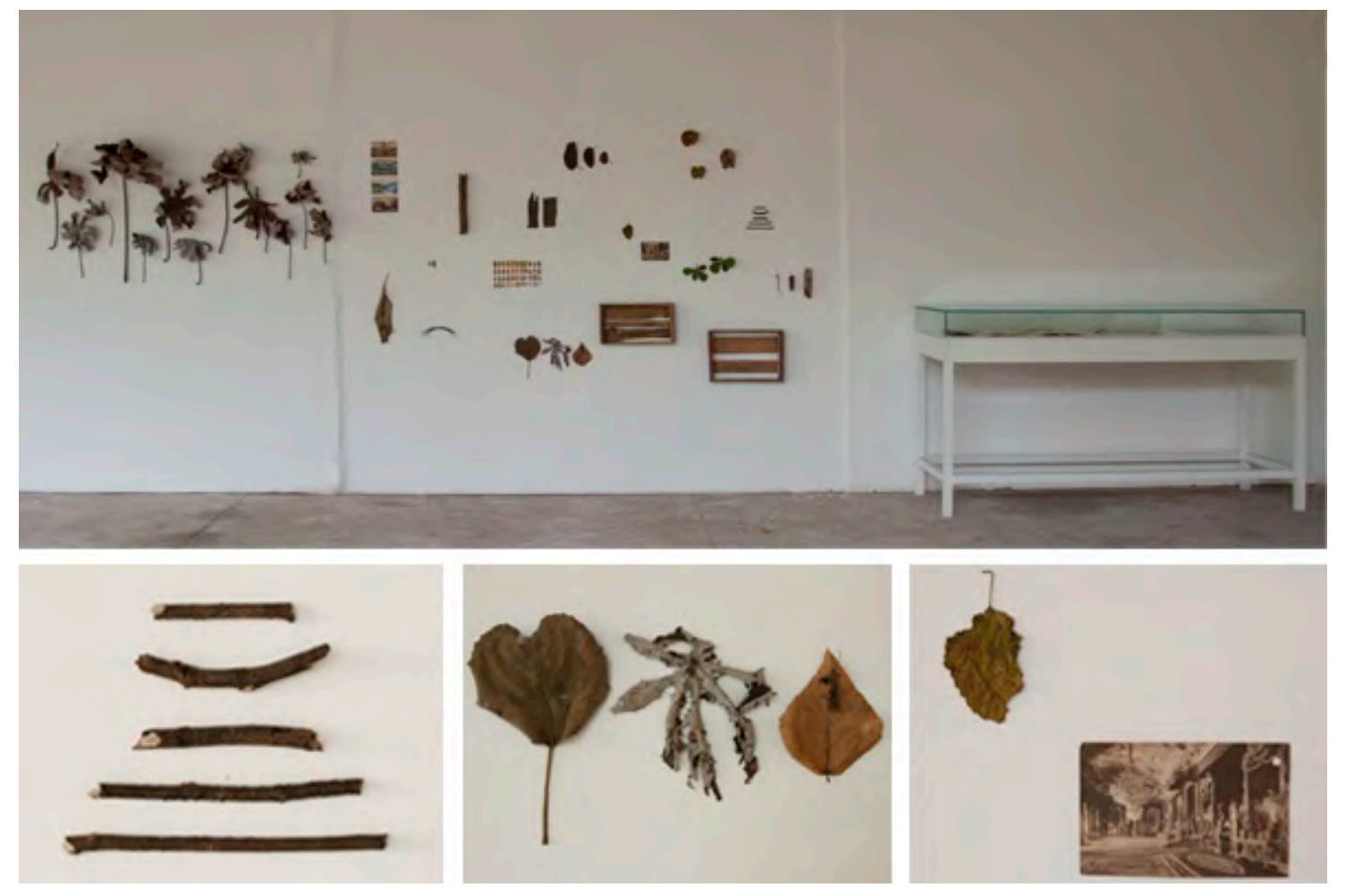

Imagem 4: Herbarium in Loco, 2011

Instalação Site-Specific.

Vegetação do subsolo do paço das artes, caixas de madeira, fichas de papel, cadernos de anotações com desenhos em nanquim, alfinetes, pregos variados, sobre parede branca.

Dimensões variáveis.

Paço das Artes - Exposição 51 Passos.

Fotos: Inês Moura.

O presente artigo debruça-se sobre um conjunto de obras de arte da artista visual portuguesa residente em São Paulo, Inês Moura. São elas: duas fotografias da série Paisagens (2012) (Imagem 1); três fotografias do estudo Our relationship explained by nature \#1 (2012) (Imagem 2); e a instalação Herbarium in loco (2011) (Imagens 3 e 4). Esta seleção é resultado da pesquisa de mestrado intitulada Juventude e arte contemporânea: indefinição e itinerância em nove obras e duas exposições de Inês Moura (Froehlich, 2013) desenvolvida entre 2011 e 2013 junto à Universidade de São Paulo. Durante 9 meses, a pesquisadora acompanhou semanalmente a artista Inês Moura em seu ateliê e, por vezes, em exposições que montara. O escopo da pesquisa pretendia desenvolver um estudo geracional a partir do pensamento visual de uma artista contemporânea e o imaginário de sua geração.

A questão que norteou a pesquisa "o que caracterizaria o imaginário de uma juventude artística entre os anos de 2009 e 2013?” reverbera neste texto ao refletirmos, a partir das descrições das obras e de seu processo de criação, sobre a manutenção do artista, dito jovem, à margem do circuito da arte. Esta indagação dialoga com a forma com que Inês, pintora de formação, 'retrata' seus motivos e o mundo em que habita. Refletimos, portanto, sobre a forma com a qual a obra se apresenta, sobre seu conteúdo e sobre o contexto da arte contemporânea (Cauquelin, 2005). Abordamos 'imaginário' como indicia Maurice Merleau-Ponty, isto é, como a visualidade invisível (Merleau-Ponty, 2011) do que se apresenta 
para aquele se expressa (da Câmara, 2005) pela linguagem muda da pintura e das artes visuais (MerleauPonty, 2004b). Ou como aponta Osvaldo Fontes Filho (2005):

O trabalho do pintor invariavelmente subverte a sábia repartição entre o real e o imaginário. O que solicita seu olhar não é um duplo irreal do real, mas o que Merleau-Ponty chama, consciente de ser contraditório nos termos 'a textura imaginária do real', ou seja, o trabalho requerido da imagem para manifestar com sua iminência o aparente sem ter de ilustrá-lo. (Fontes Filho, 2005, p. 106).

Sendo o objeto geral o imaginário de artistas, por que eleger um? Partiu-se do princípio que o recorte haveria de ser feito em um momento ou outro. Assim, dado que os discursos sobre os artistas em geral dificilmente alcançam suas vivências, a escolha foi aprofundar na vivência de uma artista e suas obras. Logo, nosso caminho foi acompanhar a criação de obras de uma "jovem artista", de forma que ela e seus trabalhos sejam pensados a partir do que eles mesmos apresentam e desvelam. "Em outras palavras, para saber o que é a subjetividade produtora, temos que partir do caso [der Fall] e não da regra ou de regras, ainda mais quando essas são abstratas e resultam de um entendimento limitado” (Werle, 2009, p. 178).

Consequentemente, não se trata, portanto, de um estudo da técnica ou da tecnologia, como a de produção de imagens fotográficas em celuloide ou digitais, ou ainda de que tipo de máquina fotográfica a artista utiliza, mas de um estudo fenomenológico dos movimentos da artista em seu processo de criação, da escolha dos motivos que dialogam com o contexto e da escolha da forma. Sendo, desse modo, um estudo de teoria e crítica da arte e de estética, e não de tecnologia, com uma abordagem fenomenológica.

Paisagens (Imagem1) e Our relationship explained by nature \#1 (Imagem 2) são fotografias, ou seja, a produção visual é feita pelo olhar da artista através de uma máquina fotográfica digital e por processos digitais, pois essas fotografias são alteradas no computador. Uma vez no computador, as fotografias são manipuladas tendo em vista o tratamento que a artista considera importantes para aquele conteúdo. Por fim, ela vislumbra um tipo e tamanho específicos de impressão e um tamanho para o mesmo. Paisagens foi visto pela pesquisadora como o díptico que se apresenta aqui (Imagem1), o qual se desdobrou em um conjunto de imagens que podem ser vistas no site da artista $^{2}$. Our relationship explained by nature \#1, em 2012, apresentou-se como um estudo ou um preâmbulo para a série de desenhos desenvolvidos por Inês Moura chamada Our relationship explained by nature \#2, as quais também podem ser vistos em seu site. Ao final do texto, disponibilizamos imagens do diário fotográfico feito durante a pesquisa no ateliê e uma das fotos (Imagem 6) retrata Inês executando um dos desenhos desta série e em outra foto a artista executando as fotografias do estudo Our relationship explained by nature \#1 (Imagem 5).

Herbarium in loco (Imagens 3 e 4) foi uma instalação e o que vemos dela são fotografias. Algumas delas constituíram a própria instalação, como registro do processo, outras são registros da instalação. Os postais, os cadernos e as fotografias constituintes da instalação ainda existem. Porém, o material orgânico exposto se desfez ao longo da própria exposição. Consequentemente, perdemos a experiência da instalação, dos desenhos, dos cadernos e das fotografias impressas. Disponibilizamos igualmente uma foto do processo de Herbarium in Loco (Imagem 7)

As obras Paisagens, Our relationship explained by nature \#1 e Herbarium in Loco, que nos direcionam neste artigo, evidenciam visualmente e em seus títulos a temática da natureza, a paisagem, o orgânico e o estudo da botânica. A última obra dialoga com as ciências que chamamos "duras” (empiristas), pela sua coleta, categorização e catalogação de espécimes de um sítio específico, como estudos de botânica e a consequente domesticação da natureza em jardins e herbários (Cauquelin, 2007).

Diametralmente, nessas obras, as plantas, as folhagens, as árvores são conteúdos dominantes, assim como a construção. A forma dada pelo quadro fotográfico ou pela instalação artística evidencia a resistência de um contra o outro, ou mesmo uma tensão. A resistência dos vegetais ao concreto, material

\footnotetext{
${ }^{2}$ http://cargocollective.com/imoura/Paisagens-Landscapes-1
} 
sobre o qual se colocam, é explorada por Inês nas obras que analisamos neste artigo. São obras distintas, mas que possuem essa temática comum: a sobrevivência da vida orgânica ante a construção humana.

\section{A sobrevivência em paisagens}

Na primeira imagem do díptico Paisagens (Imagem 1), vemos ao fundo uma mureta de tijolos. A mureta está no centro do quadro; o muro é contornado por fileiras de árvores. Este caminho, que parece ter sido traçado para levar à mureta, está coberto de grama.

Na foto em preto e branco há sombras que conduzem o olhar do espectador em direção ao muro. O muro de tijolos, por fim, pode ser um vestígio de atividade humana, por ser uma construção abandonada, esquecida. De um rastro a outro, nosso olhar vagueia em uma única via, porém de mão dupla: das árvores para o muro e do muro para as árvores. A tensão entre a matéria concreta e a mata se instala no olhar daquele que vê.

O muro está como que isolado do entorno ou seu entorno são as árvores. O seu isolamento e seu suposto abandono são evidenciados pelos elementos recortados pelo quadro fotográfico, pelo ponto de vista eleito pela artista. O muro, na foto, está ao longe, no ponto de fuga e tal distanciamento enfatiza o caráter de vestígio da construção. O muro está distante no quadro fotográfico, no tempo e no espaço do observador da foto. Dessa maneira, o enquadramento eleito pela artista reforça esse abandono da construção humana em meio a natureza que a consome. As árvores e a grama dominam o quadro, o conteúdo da imagem, assim como avançam sobre a construção abandonada. Há também um rastro de luz, uma iluminação indicada pela diferença de tons de cinza da foto. Esta luz clareia as folhagens e, à medida que nos aproximamos do muro, a mata adensa-se nas sombras.

A concretude do muro, daquele que se coloca na natureza como fixidez, uma vez colocado, se não houver uma ação humana que o retire, ele lá permanecerá. No entanto, abandonado pelos indivíduos que o mantêm rígido, ele é tomado pela natureza, pelas plantas, pelos animais, e pelas ações do vento, das chuvas. Ou seja, apesar do cimento e do tijolo, há a organicidade do mundo, sua flexibilidade, maleabilidade e fluidez.

Por outro lado, na segunda fotografia do par que compõe a obra Paisagens, vemos um par de muretas em primeiro plano. Elas são dadas ao olhar do espectador de imediato. Indicam uma circularidade como o bocal de um poço. As árvores o cercam, no entanto, mais distantes do que o muro, da imagem anterior, que está imerso nas árvores. O segundo poço está imerso nos musgos, na vegetação rasteira que o cobre.

As árvores traçam linhas verticais. No primeiro plano, vemos também um galho quase sem folhas que invade a abertura do poço, uma folhagem rasteira que o cerca e pequenos musgos. Portanto, as árvores não o cobrem, mas musgos e folhagens rasteiras. A construção nas duas fotografias está coberta por organismos vivos. O poço lá permanece, inerte e consumido pelo mundo orgânico que o cerca.

Este poço da segunda fotografia funciona também como um fosso entre o espectador e a floresta ao fundo. As duas fotografias de Paisagens propõem questões sobre a proximidade e a distância do objeto construído e da natureza. Qual a nossa proximidade e nossa distância em relação às coisas? Martin Heidegger (1889-1976) pode nos ajudar a iluminar a questão que vemos nos dois enquadramentos de Paisagens. No início do texto A coisa (Heidegger, 2002) o filósofo escreve: "O homem está superando as longitudes mais afastadas no menor espaço de tempo. Está deixando para trás de si as maiores distâncias e pondo tudo diante de si na menor distância” (Heidegger, 2002, p. 143)

A artista coloca o embate entre a construção abandonada e a vegetação na frente do espectador por via da fotografia. No entanto, no jogo das duas imagens (Imagem 1) entre o muro ao longe e poço próximo, Inês evidencia essa proximidade distante que mantemos de ambos, tanto da construção, quanto da natureza que lá está. 
Nos termos de Heidegger (2002):

E, no entanto, a supressão apressada de todo distanciamento não lhe traz proximidade. Proximidade não é pouca distância. O que na perspectiva da metragem, está perto de nós, no menor afastamento, como na imagem do filme ou no som do rádio, pode estar longe de nós, numa grande distância. (Heidegger, 2002, p. 143)

Logo, por mais próximo de nós, observadores da imagem, que o poço ou as árvores possam estar, na concretude da experiência é a ordem de um tempo e um espaço desmedido que se coloca. As correlações entre luzes, em tons que vão dos claros aos escuros, verticais e horizontais, formas e materialidades, igualmente, introduz a atmosfera temporal.

Temos, ainda, outro jogo no par fotográfico. O observador pode se perguntar se é a natureza que resiste ao poço ou o poço que resiste à tomada da vida orgânica. As fotografias de Paisagens evocam esse olhar da natureza que sobrevive às ações dos indivíduos. De modo análogo, as marcas que alguém deixa como herança permanecem para gerações seguintes. O vestígio de construção sem autoria torna o material mais enigmático, como uma obra de arte sem autor. Essas duas fotografias possuem, portanto, um mistério. O mistério da presença a partir da ausência.

As duas fotografias de Paisagens foram eleitas por Inês em meio a muitas outras de uma viagem pelos arredores de Coimbra, em Portugal. Com seu pai guiando, Inês ia parando a cada construção consumida por plantas, em busca dessa tensão entre o orgânico e o inorgânico construído na paisagem. Como vimos, interessa-lhe o embate, que pode ser entre o novo e o antigo.

O antigo e o novo, nestas duas fotografias, são ambíguos, pois o novo pode ser a construção que foi implantada em meio às antigas plantas que habitavam o local. Por outro lado, o novo pode ser as plantas que nascem e crescem sobre o poço e o muro. Há uma tensão constante entre o novo e o antigo no próprio tema eleito pela artista. Esse embate entre os elementos distintos das imagens pode ilustrar a tensão do jovem frente ao maduro e vice-versa, pois essa oposição de materialidades (orgânico x inorgânico) ajuda-nos a compreender a resistência da juventude e da maturidade, uma em relação à outra. Este par fotográfico de Paisagens aborda algumas faces da tensão entre a matéria nova e a matéria antiga. Não sabemos o que veio antes na fotografia, a vegetação ou o muro e o poço. Notemos que não se trata de definir, mas de apontar que o novo ou o velho é uma questão de "perspectiva". O par de fotografias proporciona pensarmos mais a tensão entre as materialidades do que toma o lugar do que.

Nesse sentido, esta tensão também figura a luta de Inês, entre outros artistas, para sobreviver de seu trabalho, de sua produção de obras de arte. A princípio, a artista, para viver de sua produção, depende da comercialização de suas obras. Para que isso ocorra, precisaria adentrar no circuito. Essa incursão no circuito se daria, em grande parte, pela constituição de um público consumidor de sua produção. O público, por sua vez, consome indo a exposições.

Inserir-se no sistema da arte é uma luta e se manter lá seria outra. Mas Inês e outros de sua geração caminham em direção a se colocar no circuito. No entanto, sendo categorizados como jovens artistas, ainda são como "marginais" do sistema da arte, são alocados marginalmente no interior de uma discussão sistemática.

Notemos que o jovem é equiparado a um marginal, mas o sendo estaria abarcando uma espécie de nicho do mercado. Inclusive por suas obras não terem ainda valor acumulado de currículo (que seria equivalente a um número de exposições, prêmios, galerias, obras em museus s). Essa veiculação "menor" do jovem garantiria um início de circulação das obras e de uma possível sobrevivência do artista a partir de sua produção. "Tenho a impressão de que o mundo da arte está recortando para si, a partir disso, um espaço de sobrevida.” (Mammí, 2012, p. 15). Isto é, ao manter o jovem na margem, ele (jovem) sobrevive, não necessariamente vive, no sentido de que o jovem artista mantém continuamente uma resistência, como as plantas sobre a construção. 
A paisagem - quando não era considerada um gênero da pintura - era utilizada na composição pictórica do Renascimento como parte do enquadramento das figuras ou dos temas representados. Segundo Anne Cauquelin (2007), a paisagem é compreendida como paisagem nos estudos de perspectiva do século XV. O que ocasionaria a domesticação de uma "natureza" pelo olhar do homem que a representa. No século $\mathrm{XV}$, a paisagem passará a representar o que viremos chamar de natureza, aqual é dada segundo a medida do homem. "A paisagem não é uma metáfora para a natureza, uma maneira de evocá-la; ela é de fato a natureza.” (Cauquelin, 2007, p. 39). Não à toa, uma suposta origem da paisagem remete ao momento do surgimento da perspectiva.

Dessa maneira, Inês, ao intitular Paisagens o conjunto fotográfico (Imagem 1), constituiria uma remissão conceitual e consequentemente visual ao conteúdo da pintura, segundo o que Anne Cauquelin (2007) descreve, pois não só o par de fotografias faz uso da perspectiva, como a perspectiva enquadra uma "natureza". Portanto, a paisagem está diretamente associada a uma discussão da perspectiva clássica, que é possível ver no uso dos enquadramentos.

Ao enquadrar a paisagem, a artista a coloca em perspectiva. De maneira que as duas imagens adentram o registro visual e conceitual da tradição da composição clássica, do homem como medida do mundo, constituintes do Renascimento (Hauser, 1995). A partir desta tradição a sua inscrição estaria no jogo das duas fotografias. Neste jogo, a artista evidencia que a medida é relativa ao ponto de vista do observador. E mesmo o título Paisagens coloca em questão o que seria a paisagem nas duas imagens.

\section{A sobrevivência em heras}

As fotografias de Our relationship explained by nature \#1 (Imagem 2) são enquadramentos de uma hera que se sustenta firmemente sobre um muro. Vemos raízes desta hera, seu tronco e suas folhas agarradas ao concreto. Há lugares da composição em que há mais folhas, outros mais raízes aparentes ou mais partes do muro sobre o qual a planta se assegura. Pelo quadro da foto, poderíamos sugerir que a máquina está próxima ao objeto a ser fotografado. E ela estava, como é possível ver nas fotografias tiradas pela pesquisadora quando Inês realizava Our relationship explained by nature \#1 - (Imagem 5).

Esta série de fotografias começa nos fundos do ateliê em que Inês trabalhava. Nos fundos, havia um pequenino jardim com algumas plantas e, entre elas, a hera que dominava o muro e separava o ateliê da casa vizinha. Para fotografar essa hera, a artista estuda minuciosamente os seus movimentos no muro. Inês fotografou pedaços da planta que se sustentava no muro com a distância de pouco centímetros.

A máquina fotográfica, nas mãos da artista, funciona como o instrumento de estudo das variadas partes do objeto que examina. Investiga através de alterações de filtro, lente e luminosidade aquilo que mais se adequa ao efeito final desejado. Efeito que o ângulo de aproximação da hera e as medidas de seu instrumento de estudo produzem em conjunto. A luz do dia influencia o padrão das fotografias, o que fez com que a artista, ao longo do dia, fotografasse sob diferentes luminosidades. Este cuidado na aproximação de seu objeto de estudo evidencia a natureza própria do método. "Pensar é ensaiar, operar, transformar, sob a única reserva de controle experimental em que intervém apenas fenômenos altamente 'trabalhados', os quais nossos antes aparelhos produzem do que registram.” (Merleau-Ponty, 2004a, p. 13). Assim, Merleau-Ponty comenta a filosofia das ciências de seu tempo. Poderíamos compreender o processo fotográfico de Inês como esse "trabalhar" os aparelhos técnicos que mais produziriam do que registrariam. De fato, mais do que registrar, ela produz. Enquanto artista, a partir da empiria, Inês produz uma visão daquele objeto. No entanto, ao invés de um suposto distanciamento de seu objeto, a artista se aproxima não só fisicamente, mas caminha pela hera procurando seus movimentos. Ela se embrenha na planta até com ela mesclar-se, sendo que seus aparelhos, a máquina fotográfica e o computador simplesmente re-produzem essa relação. "A artista está ali, forte ou fraca na vida, mas incontestavelmente soberana em sua ruminação do mundo, sem outra "técnica" senão a que seus olhos e suas mãos oferecem à força de ver, [...]” (Merleau-Ponty, 2004a, p. 15) 
Portanto, artista e investigadora, Inês estaria imersa “[...] no visível por seu corpo, ele próprio visível, o vidente não se apropria do que vê; apenas se aproxima dele pelo olhar, se abre ao mundo.” (MerleauPonty, 2004a, p. 16). Essa abertura visual ao mundo a interpela nas direções do olhar através da câmera. Diferente do pintor, figura a qual Merleau-Ponty faz referência, ela não mistura tintas e tampouco usa pincéis, mas regula sua máquina fotográfica usando tons, formas e volumes.

Inês disse, ao fotografar essa hera, que aquilo que lhe interessava eram os efeitos de planos que as folhas formavam e o destacamento dos galhos que formavam planos e, portanto, volumes, na bidimensionalidade da fotografia. A tensão identificada nas imagens de Paisagens pode ser igualmente reconhecida na série de Our relationship explained by nature \#1, na hera que cresce sobre o muro, como a folhagem sobre e ao redor do poço. O tronco da hera sustenta-se pouco a pouco no muro. Uma vez bem fixo e espalhado sobre o concreto, o tronco lavra seus galhos. Sugerindo que, uma vez bem fixado, é possível avançar no desenvolvimento do vegetal. Nesse sentido, a tensão estaria nesta sustentação de um pelo outro, pois o muro sustenta a hera. Porém, a hera protege o muro da ação de outros fatores como a chuva e o vento. Assim, um dependeria do outro, a planta para o seu crescimento e sobrevivência e o muro para continuar inalterado por outros fatores.

A própria hera alteraria características do concreto, pois faz inserções nele para se fixar. Essas inserções da hera só podem ser vistas se a planta for arrancada da superfície em que está. Nesse âmbito, em harmonia, um complementaria o outro. Do mesmo modo que em Paisagens, a tensão entre novo e antigo coloca-se pela temática em Our relationship explained by nature \#1. A hera pode ser compreendida como o elemento novo que se coloca sobre o antigo. O muro sustenta a hera, como se o antigo sustentasse o novo. Desse modo interpretamos que o novo na arte, ou seja, o jovem artista, poderia crescer e desenvolver novas proposições artísticas ao estar muito bem fixado na tradição, a qual, como delimitada anteriormente, seria todo o conhecimento disponível ao artista, do qual ele pode apropriar-se.

Nesse sentido, o jovem artista inscrever-se-ia na tradição, à qual deve se referir e se sustentar, contudo, a tradição só existe pelo próprio avanço de novas gerações. Portanto, a prática frequente do jovem, que é artista e que pretende inserir-se no circuito da arte, é partir do estudo rigoroso, atento e contínuo de produções visuais ao longo do acúmulo de história e teoria da arte. E, sobretudo, das técnicas que permitem ao iniciante e aprendiz dominar a linguagem que elege como sua.

O estudo da arte, veiculada, no caso de Inês Moura, pela universidade, ancoraria conhecimento, repertório visual e conceitual do domínio das artes visuais. Assim, as produções selecionadas por uma história e reconhecidas no sistema fariam parte da formação de Moura e alguns de sua geração. Inês Moura teve uma formação, segundo ela, "tradicional”. Formada na Faculdade de Belas Artes de Lisboa, seus conhecimentos técnicos e teóricos em pintura e desenho estariam, por essa formação, diretamente ancorados na tradição. Além do contato com a arte na faculdade, frequentava exposições assiduamente, de forma que pode compreender suas obras em relação ao que o circuito apresenta.

O contato e a volta ao passado para apontar sua produção em direção a um futuro localiza a artista e seus pares neste presente tensional. Entre o que foi e o que pode ser. Vários artistas jovens da mesma geração de Inês examinam uma vertente da tradição a fundo, tradição que os sustenta a ponto de abrir perspectivas de futuro. Isto é possível “ver” em obras de artistas atuais e jovens que trazem a discussão de um passado cultural, científico e artístico (Froehlich, 2013). 


\section{A sobrevivência efêmera}

Herbarium in loco (Imagens 3 e 4) foi uma instalação desenvolvida por Inês como trabalho final de um curso que o artista e professor da UNESP ${ }^{3}$ José Spaniol ministrava no subsolo do Paço das Artes ${ }^{4}$ no segundo semestre de 2011. O curso foi composto por alguns alunos da UNESP e outros artistas de lugares distintos. Desta experiência, sob coordenação de Spaniol, resultou uma exposição dos trabalhos de seus alunos. Essa exposição foi intitulada 51 passos.

Para sua instalação, Inês desenvolveu a proposta de um herbário feito da coleta das plantas existentes em pequenos espaços no subsolo do Paço das Artes. Com tal finalidade, ela começa munida de uma máquina fotográfica digital, fichas, lápis e caixas de madeira usadas (como essas de feira para frutas e verduras) e, então, com esse material, fotografa, coleta e anota algumas observações em suas fichas. O material orgânico coletado é colocado junto às suas anotações correspondentes. Ambos, material orgânico e ficha, são guardados conjuntamente em pequenos sacos de papel feitos pela artista e colocados nas caixas de madeira. Depois da coleta e separação dos delicados objetos orgânicos ela os desenha em um caderno, também feito por ela.

Os cadernos são expostos como parte do processo de coleta, assim como as fichas catalogadas e as caixas que serviam de coleta. O conjunto de imagens do processo de criação desta instalação (Imagem 3), que apresentamos aqui, é composto por registros da instalação final (Imagem 4), do processo e da coleta do material. Inês incorporou os registros fotográficos de pesquisa à instalação.

Na exploração do local, na observação, na coleta, nas fotografias, nas fichas com observações, nos desenhos e, por fim, na montagem da instalação foram feitos registros e estudos do material orgânico recolhido no subsolo do Paço das Artes. Nesse sentido, podemos deduzir que a instalação seria como um "artigo científico visual”. Isto é, ela organiza visualmente o material que é resultado da pesquisa que fez no espaço do subsolo da instituição.

De maneira análoga a um artigo escrito, a artista dispõe para o espectador o conceito da pesquisa, o método e os resultados. O conceito estaria contido no título e na forma da instalação, sendo esta o próprio tema da pesquisa. O método seria as fotografias do material, o caderno de desenhos e as fichas. Finalmente, os resultados são garantidos pelos postais antigos de paisagens colocados em meio às plantas, folhas, galhos e caixas dispostos na instalação. A forma final, fruto de pensamento vivido, faria parte também dos resultados da investigação do espaço.

Os postais são materiais externos ao subsolo onde Inês praticou sua "botânica”. No entanto, podem ser vistos como referenciais de paisagens. Como uma composição visual do passado colocada à disposição para a discussão da pesquisa. Ela coleta, ao longo de sua vida, fotografias e postais antigos. Os postais são fotografias de paisagens, as quais provavelmente, não existem mais. Em Herbarium in loco, a artista opera, praticamente, como uma cientista. Inês escava e explora cada centímetro do local em busca de suas especificidades, das matérias esquecidas e/ou abandonadas no subsolo da instituição.

A instalação, como nas obras de Inês que discutimos antes, evidencia o embate da natureza com o concreto, como a natureza invade um espaço quase abandonado. No entanto, em Herbarium in Loco, o orgânico, as plantas, seus galhos e folhas, são cuidadosamente recolhidos e dispostos. São colocados, neste trabalho, sobre o muro.

A tensão entre o objeto construído e "natureza”, da qual falávamos há pouco, aqui não é mais mantida, pois a natureza, a paisagem em forma de herbário, é elevada ao lugar dos olhos do público. Dessa forma, o orgânico demanda a atenção do observador e a natureza é forçosamente dissecada. A artista "cuida"

\footnotetext{
${ }^{3}$ Universidade Estadual Paulista “Julio Mesquita Filho”.

${ }^{4}$ O Paço das Artes "foi criado em março de 1970, com o intuito de organizar e manter exposições de arte; promover conferências, cursos, palestras e audições; divulgar os assuntos ligados à área de sua especialidade e promover intercâmbios.” Disponível em http://www.pacodasartes.org.br/sobre.aspx. Acesso: 31 de janeiro de 2018.
} 
de seu objeto de estudo aos olhos do espectador, porque o mundo natural, seu objeto, lhe é constituinte. "Visível e móvel, meu corpo conta-se entre as coisas, é uma delas, está preso no tecido do mundo, e a sua coesão é a de uma coisa" (Merleau-Ponty, 2004a, p. 17). À medida que a artista se embrenha entre concreto e folhagem, seu corpo é imerso e como que atravessado por aquele local. Condição de "uma coisa” só, ou seja, ela e seu ambiente, que é seu objeto, são um.

Nesse sentido, seria mais interessante explorar a relação inversa, na qual a artista trabalha a ciência artisticamente. A partir dos métodos científicos de compreensão do mundo empírico, do rigor, do contato direto com o objeto e das representações do passado, a artista tematiza não só a ciência, mas o próprio contato do homem com essa "natureza". Natureza compreendida como representação.

Anne Cauquelin (2007), como vimos anteriormente, aponta para a representação da natureza na pintura de paisagem. A pintura regeria uma compreensão do mundo natural a partir de uma representação desse mundo. Teríamos, então, "uma proximidade entre arte e natureza, pois uma representa a outra." (Merleau-Ponty, 2004a, p. 39). A natureza representada pelo homem do Renascimento estaria à medida dele.

No trabalho de Inês, isso é reposicionado, pois coloca lado a lado a paisagem fotografada do postal, as plantas recolhidas no espaço e as fotografias das plantas que fazem parte da instalação. O material orgânico e a suas imagens entram em conflito. A natureza e seu imaginário são apresentados ao espectador. Inês não utiliza somente a imagem de paisagem, mas parte de um mundo natural in loco, considerando que aquilo que há aqui de natural é igualmente questionado, visto que as plantas são parte de um ambiente controlado.

Por outro lado, Herbarium in loco, assim como Paisagens e Our relationship explained by nature \#1, poderiam ser pensados como um discurso ecológico em que a "natureza" e o homem estão em conflito, pois abordam conteúdos visuais que abrangem este conflito, por exemplo, no olho ordenador que "salva" pequenos trechos de folhagem, plantas, matas e florestas (nas fotografias). Mas Inês não é propriamente uma "artista-ativista". O cuidado na coleta de folhas, sua categorização e as fotografias de paisagens e jardins leva-nos a revisitar esse mundo natural controlado na paisagem, no jardim e no herbário, o qual faz parte do mundo atual. "Jogos com ervas, as folhagens e as formas abstratas que o paisagista pode impor como intervenção meio-artificial, meio-natural.” (Cauquelin, 2007, p. 173).

O instrumental e as ferramentas do jardim não devem ser esquecidos, como fez a artista ao colocar as caixas de coleta na instalação. Na obra Herbarium in loco, Inês, mais uma vez, assume uma tradição, seja da jardinagem, seja da construção científica, que opera como referência na discussão dos resultados. A tradição visual artística e científica não é subvertida, ou rompida por ela, mas incorporada. Mais uma vez, a tradição é assumida e rigorosamente interrogada pela forma em consonância com seu conteúdo na obra. A artista interroga esse arcabouço visual e conceitual das artes visuais e das ciências em geral, questionando, assim, seu lugar como jovem, artista e pesquisadora.

O processo meticuloso de fotografar o material orgânico, catalogar e expor faria parte de prerrogativas científicas, ou mesmo das ciências que se ocupam das artes, como fazem os museólogos. E Inês reposiciona-as. Não discute uma crise das ciências ou o que seria o estado atual das artes, mas como as disciplinas dialogam entre si. Em suma, a artista figura a interdependência entre artes e as ciências.

No trabalho de Inês, a natureza, enquanto conceito artístico e visual, é colocada à altura dos olhos. Tal configuração visual e espacial visa à discussão sobre os limites entre arte e ciência. Herbarium in loco, de Inês Moura, retoma um imaginário científico do passado que é retomado nesta época que chamamos presente pela forma de site-specific, a qual indica uma relação efêmera. Segundo Miwon Kwon (2002), "a arte site-specific inicialmente entende o sítio/local como um local efetivo, uma realidade tangível, sua identidade é composta pela combinação única de elementos físicos” (Kwon, 2002, p. 11) ${ }^{5}$. Ou seja, no

\footnotetext{
${ }^{5}$ Tradução nossa. Site-specific art initially took the site as an actual location, a tangible reality, its identity composed of a unique combination of physical elements.
} 
site-specific o espaço seria tomado como matéria para a qual o artista dá forma. Considerado em sua especificidade de matéria situada, o site-specific depende do lugar em que está e das características prévias que este local possui, sejam construídas, sejam naturais.

Por outro lado, o artista que produz e denomina uma obra "site-specific" transformaria um sítio espeíifico em um sítio especificamente artístico. Logo, além da obra ser especificamente daquele local, o próprio lugar torna-se específico da obra. Dessa forma, muitas instituições fazem uso de site-specifics. Como escreve Hal Foster (1996), "neste caso a obra site-specific pode ser utilizada para fazer esses não-espaços parecerem específicos de novo, para compensá-los como lugares fundamentados, não mais espaços abstratos, em termos históricos e/ou culturais” (Foster, 1996, p. 197) ${ }^{6}$.

Nas décadas de 1960 e 1970, o site-specific era uma linguagem que se pretendia ir em direção contrária às instituições artísticas, pois as obras eram feitas fora do circuito tradicional, como as obras de Gordon Matta-Clark (1943-1978) e Robert Smithson (1938-1973). No entanto, essa forma foi absorvida pelo sistema, que faz uso dessa especificidade. Uma instituição valoriza-se e se legitima, na atualidade por ter obras únicas feitas somente para um local.

Hal Foster (1996) alerta para o risco de artistas fazerem um trabalho com essas características dentro ou a partir de ambientes institucionais, dado que o site-specifc tornaria "não espaços" em espaços novamente. Herbarium in loco pode operar como uma revitalização do espaço do subsolo da instituição em que foi feito, a qual, por sua vez, buscaria ampliar seu potencial de locais para exposições ${ }^{7}$. No entanto, pelo fato de Inês ser considerada, até aquele momento, como “jovem artista” e a exposição ter durado poucos dias, o seu site-specific não transformaria por si mesmo o subsolo num lugar especificamente artístico. Assim, o subsolo ainda permanece com um uso restrito e o trabalho de Inês não foi institucionalizado. Ao final, ao expor as plantas que ocupam o lugar desocupado do subsolo, Inês Moura igualmente expõe o abandono e o uso marginal do espaço institucional ${ }^{8}$.

Ao ser definido como um "sítio específico”, Herbarium in Loco também se configuraria como uma obra efêmera, pois, uma vez desmontada a instalação, esta não poderia jamais ser re-visitada. A obra efêmera faz parte de um único local, o que torna aquele local ainda mais específico, uma vez que somente naquele tempo e naquele espaço foi possível ver aquela instalação de Inês Moura. "Ora, a arte contemporânea muitas vezes opera sob o signo da não-disponibilidade, apresentando-se num momento determinado" (Bourriaud, 2009, p. 41).

A efemeridade deste trabalho de Inês não corresponde apenas à forma ou ao conceito, mas aos próprios materiais utilizados. A matéria coletada, catalogada e exposta junto com seus respectivos registros, é orgânica. Isto significa que, ao longo do tempo, ela se modifica, podendo mesmo desaparecer. O subsolo, onde estava a exposição, é aberto por todos os lados e o trabalho de Inês ficou próximo a uma dessas aberturas. Sujeita a alterações climáticas, a matéria orgânica modificou-se. Por exemplo, as folhas que secaram ao longo da exposição ou passaram do tom verde para o amarelo, evidenciam a passagem do tempo nos materiais.

Portanto, Herbarium in loco é uma obra "site-specific" efêmera. Isto é, tem uma duração específica no espaço e no tempo. O que restou desta instalação foram registros fotográficos e as observações feitas, tanto em desenho, quanto em textos. Expondo os resultados da investigação do espaço, a instalação aborda o diálogo entre arte e ciência, de modo que corrobora perguntas como: "Porque o mundo é o que é, em vez de outra coisa?”(Merleau-Ponty, 2000, p. 140). Para responder questionamentos como este,

\footnotetext{
${ }^{6}$ Tradução nossa. In this case site-specific work can be exploited to make these nonspaces seem specific again, to redress them as grounded places, not abstract spaces, in historical and/or cultural terms.

${ }^{7}$ Curioso notar, que a instituição Paço das Artes ocupava um espaço pertencente à Universidade de São Paulo e em 2016 o Paço das Artes perdeu esta sede.

${ }^{8}$ O mesmo subsolo foi usado para a feira de arte PARTE. Considerada uma feira de trabalhos recentes e, portanto, mais baratos. Muitas das obras comercializadas nesta feira eram de novos artistas, ou os jovens da geração que tratamos aqui. Podemos associar que a esfera periférica do jovem artista sobrevive, como as plantas que sobrevivem ao concreto.
} 
Inês parece voltar ao passado, procurando compreender a si mesma como artista em seus métodos, conteúdos e linguagens.

\section{Considerações finais}

Ao selecionar quadros fotográficos que nos dão a ver plantas que nascem sobre muros, ou ao elevar sobre os muros de uma exposição as plantas que avançam em um subsolo, Inês nos possibilita vislumbrar nessas obras um embate entre organismos flexíveis (vegetação) e material rígido (concreto). Vemos, a partir das imagens, esse embate e sobrevivência dos artistas na tentativa de expor, dar "vida" a suas obras aos olhos de um público. Como as plantas que sobrevivem no concreto, que nele se agarram, o abraçam, envolvem e ocupam. O muro e o concreto também resistem à ocupação de novas formas de vida, podendo ser compreendido como ponto de ancoragem e de lastro.

A presença de obras artísticas que circulam no sistema da arte ou que fazem parte da história e a ausência de seus produtores, dos artistas que as criaram, é análoga à presença de pedaços de construção que vemos em Paisagens. A presença da ausência perpassa igualmente esses trabalhos, nos quais o quadro fotográfico foca o rastro da presença humana, como um poço esquecido ou um muro escondido sob uma hera. Como uma planta que nasce sobre o concreto, o jovem que é artista depara-se com tudo que existe antes dele, ou seja, com uma "tradição" de produção visual, de arte e de obra.

O recurso fotográfico garante o registro pontual, de um momento no tempo e no espaço, podendo indicar um passado. Logo, ocasiona uma experiência de nostalgia deveras frequente. A nostalgia estaria na própria escolha da técnica e na evocação de um rastro humano, como a construção, que está frequentemente envolta pela matéria orgânica nessas obras. Aquilo que chamamos natureza, vida, organismos estaria em embate com aquilo que chamamos construções humanas. Estas construções seriam como vestígios de outras pessoas, que talvez não existam mais. A construção seria a presença da ausência da figura humana nas fotografias.

As obras aqui abordadas aparentam resgatar o passado, de forma que isso lhe sustente para um avanço em direção ao seu futuro. O passado e os limites das disciplinas do conhecimento são colocados insistentemente à prova, como se existisse algo da cultura visual a ser constantemente revisitado. Apesar das tecnologias disponíveis, a artista supostamente não as explora enquanto tais, pois se serve delas como meios para explorar outras linguagens; para pesquisar a pintura, o desenho, a escultura e a fotografia na busca de seu estado mais puro. Depurando o passado e suas linguagens e depois misturando-as, Inês aponta para uma volta ao passado em signos sutis em conteúdo e forma, para refletir sobre o devir. Portanto, a tradição não é estranha ou oposta, e sim constituinte de seu imaginário. Ela faz parte do repertório da geração de alguns jovens artistas ou, como coloca Rancière (2009), "o regime estético das artes é, antes de tudo, um novo regime da relação com o antigo” (Rancière, 2009, p. 36). Este novo regime se apresentaria como uma tentativa de inserção nessa mesma tradição, em novas constelações de signos que a artista explora. 


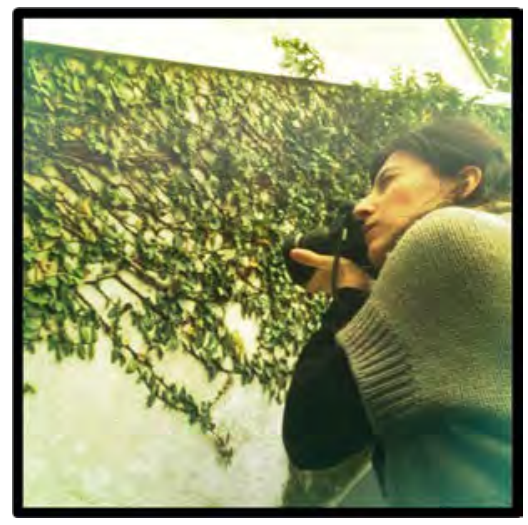

Imagem 5 - Inês Moura fotografando a hera para o estudo Our relationship explained by nature \#1 Foto: Juliana Froehlich

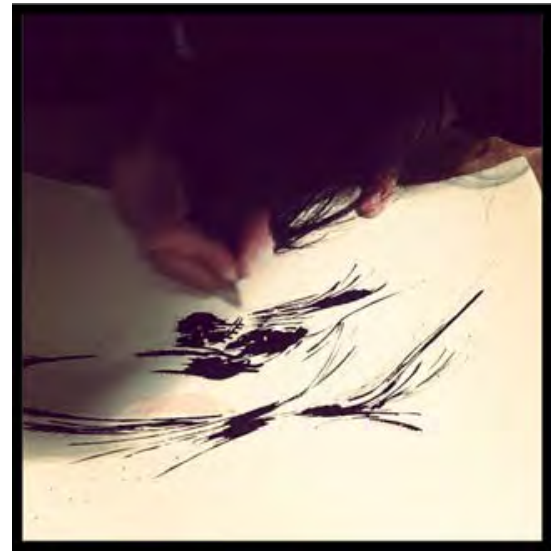

Imagem 6 - Inês Moura em desenho da série Our relationship explained by nature \#2 Foto: Juliana Froehlich

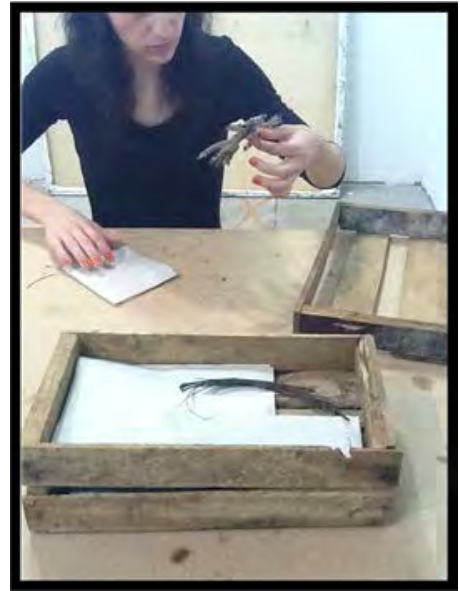

Imagem 7 - Inês Moura preparando material para instalação Herbarium in loco

Foto: Juliana Froehlich

\section{Referências bibliográficas}

Bourriaud, N. (2009). Estética Relacional. São Paulo: Martins Fontes.

Cauquelin, A. (2005). Arte contemporânea : uma introdução. São Paulo: Martins Fontes.

Cauquelin, A. (2007). A Invenção da paisagem. São Paulo: Martins Fontes.

Costa Pinto, S. http://cargocollective.com/sofiacostapinto.

da Câmara, J. M. B. (2005). Expressão e Contemporaneidade: A arte moderna segundo Merleau-Ponty. Lisboa: Imprensa Nacional - Casa da Moeda.

Fontes Filho, O. (2005). Merleau-Ponty e a" obscuridade moderna" segundo a arte. ARS (São Paulo), 3(6), 102-121.

Foster, H. (1996). Return of the real the avant-garde at the end of the century. Cambridge: MIT Press.

Froehlich, J. (2013). Juventude e arte contemporânea: indefinição e itinerância em nove obras e duas exposições de Inês Moura. (Master Master), Universidade de São Paulo, Programa de Pósgraduação Interunidades em Estética e História da Arte.

Hauser, A. (1995). História social da arte e da literatura: Martins Fontes.

Heidegger, M. (2002). A coisa. In M. Heidegger (Ed.), Ensaios e conferências. Petrópolis: Vozes.

Kwon, M. (2002). One place after another. Site-specific art and locational identity. Cambridge, London: The MIT Press.

Mammí, L. (2012). O que resta: arte e crítica de arte. São Paulo: Companhia das Letras.

Merleau-Ponty, M. (2004a). O olho e o espírito. São Paulo: Cosac \& Naify. 
Merleau-Ponty, M. (2011). Le monde sensible et le monde de l'expression. Cours au Collège de France. Notes, 1953. Genève: Metis Presses.

Merleau-Ponty, M. ( 2004b). A linguagem indireta e as vozes do silêncio. In M. Merleau-Ponty (Ed.), O olho e o espírito (pp. 65-119). São Paulo: Cosac \& Naify.

Moura, I. http://cargocollective.com/imoura.

Rancière, J. (2009). A partilha do sensível: estética e política. São Paulo: EXO experimental org; Editora 34.

Werle, M. A. (2009). Subjetividade artística em Goethe e Hegel. In P. F. Galé \& M. A. Werle (Eds.), Arte e filosofia no idealismo alemão. São Paulo: Editora Bacarolla. 